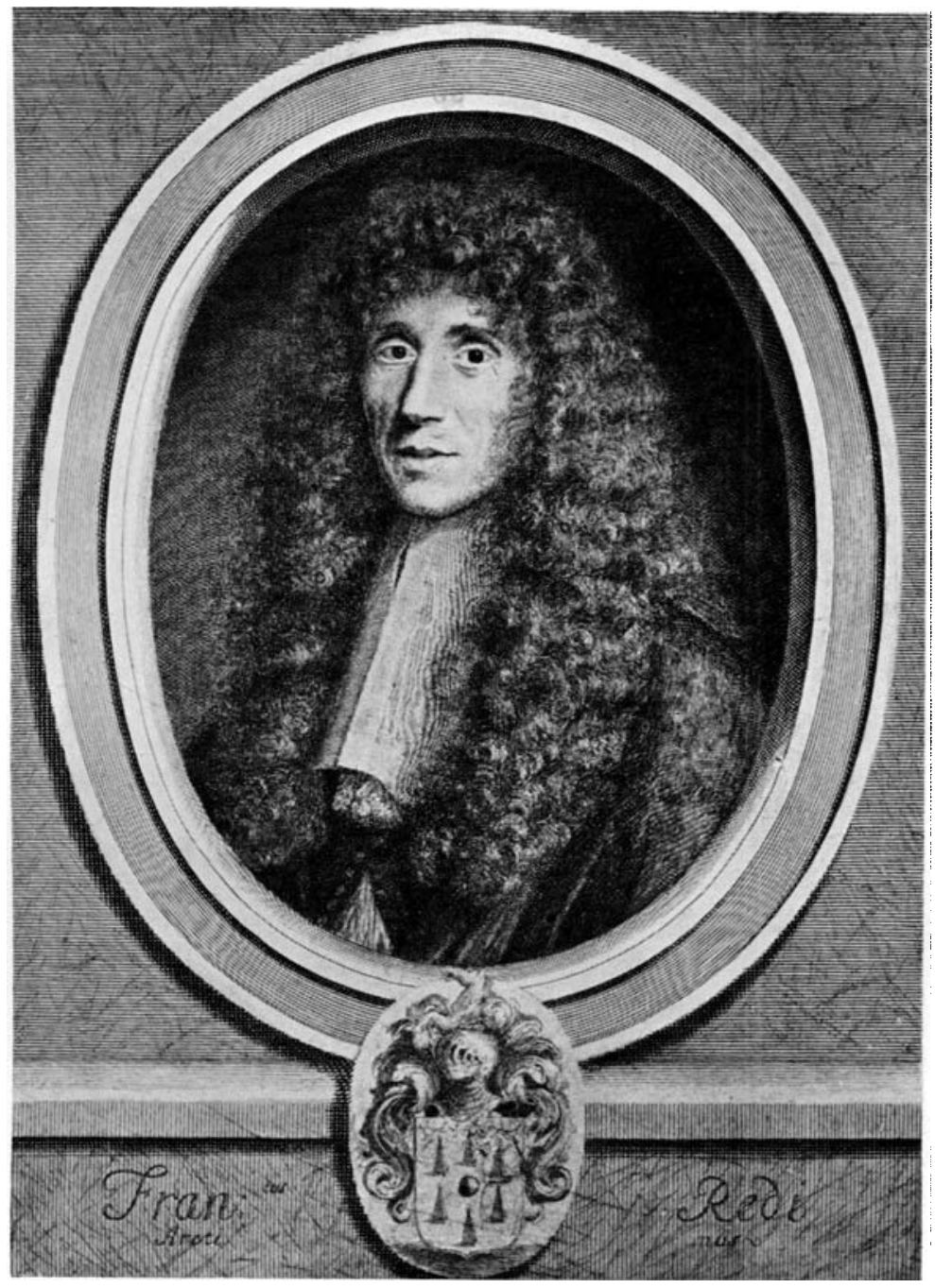

\title{
FRANCESCO REDI
}

$1626-1697$ 


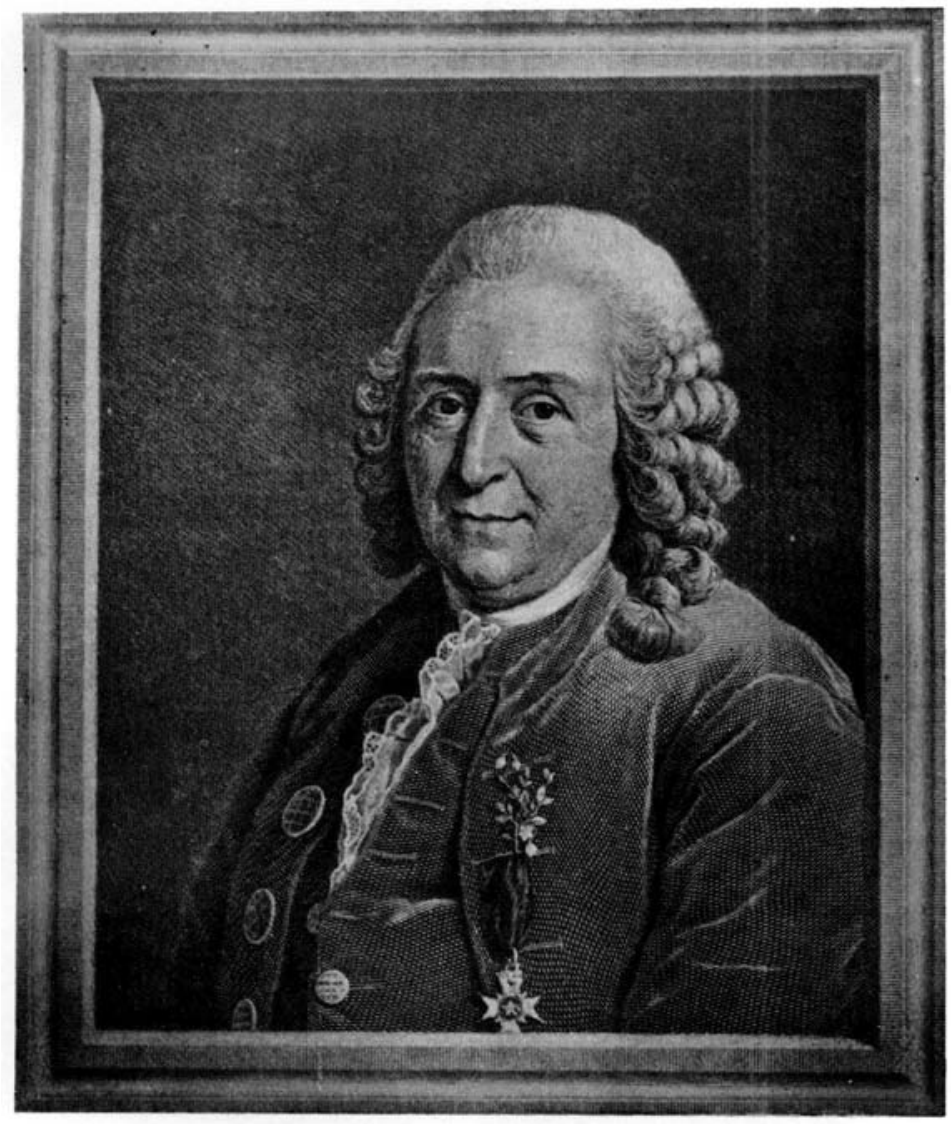

\section{CAROLUS LINNAEUS}

$1707-1778$ 


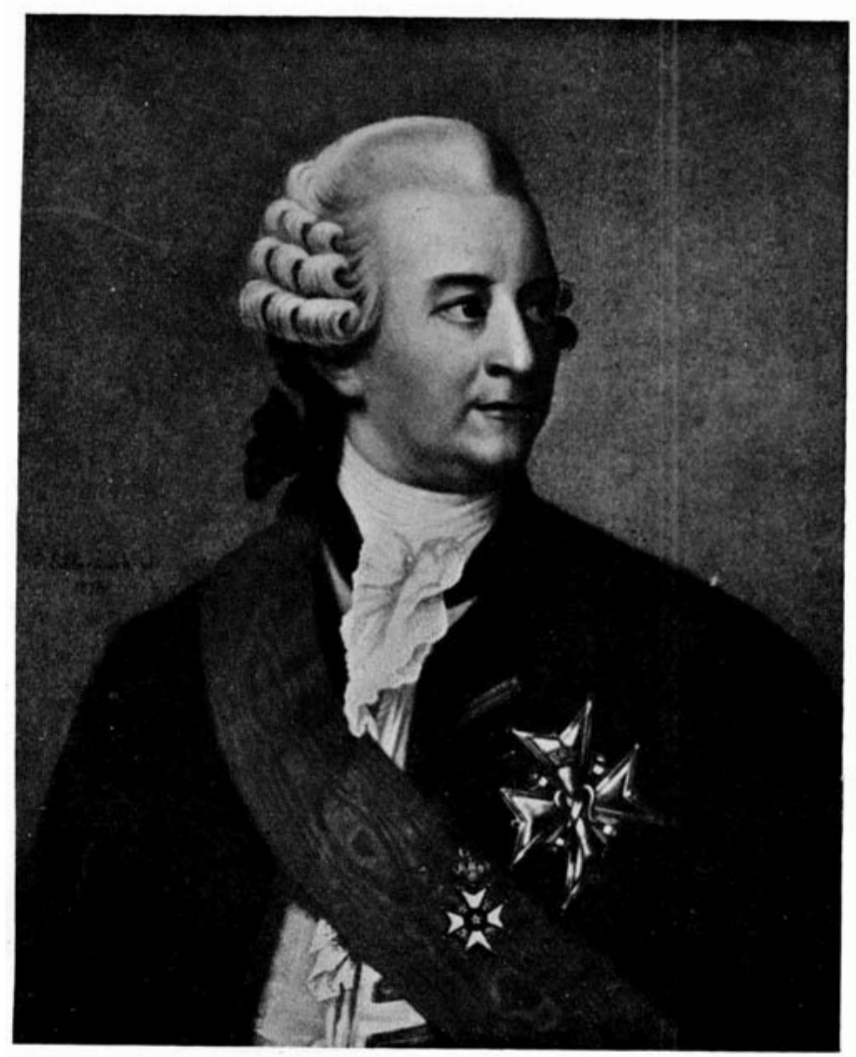

\section{CARL DE GEER}

$$
1720-1778
$$




\section{NOTICE TO AUTHORS OF PAPERS INTENDED FOR PUBLICATION IN PARASITOLOGY.}

Owing to the greatly increased cost of publication authors are earnestly requested to present their papers in as concise a form as possible. Wordiness too frequently causes delay, trouble and unwarranted expense. Unnecessary details relating to experiments should be omitted and tabular matter especially should be curtailed to a minimum because of its high cost.

\section{Manuscripts.}

MSS. should be type-written or at least written in a legible hand on one side of each sheet of paper. The pages of the MS. should be numbered. They should be carefully prepared for press so as to lessen the cost of corrections. It is an all too frequent burden upon the Editor to have to correct the grammar, spelling and punctuation of inconsiderate writers. Sufficient space should be allowed between the lines for alterations if required. The divisions in the text should be indicated by appropriate headings, corresponding in wording to those enumerated in the table of Contents that in most cases should follow upon the title of the paper. A multitude of small paragraphs is not desirable.

Care should be taken that the title of the paper shall clearly indicate its contents. Where scientific names of animals or plants occur in the title, provided such names are not commonly known, authors should state to what Order or to what Order and Family they belong, this being added in parenthesis as indicated in the following examples: Melinda cognata Meigen (Diptera, Calliphorinae), Maupasella nova Cépède (Ciliata, Astoma), Cladorchis subtrietrus Rudolphi (Trematoda). Authors who observe this rule will greatly facilitate the work of readers, indexers and others who deal with the classification of scientific literature.

If any part of the MS. is to be printed in small type kindly indicate by adding a line at the side of copy.

Tables, Legends and References should be written on separate sheets from the rest of the manuscript since they are printed by means of a different type. Authors should be sparing in the use of footnotes. Tables, legends, etc., should be numbered and the place where they are to be inserted in the text should be indicated by corresponding numbers in the margin of the MS.; authors should not refer to the "foregoing" or the "following" table since the position of the table or reference on the printed page does not necessarily agree with that on the manuscript.

Measures and Abbreviations. The metric system of measurements should be used, abbreviations being employed as follows: $\mathrm{cm}$. (centimetre), $\mathrm{mm}$. millimetre), $\mu$ (micron), kgm. (kilogramme), gm. (gramme), cgm. (centigramme), 
mgm. (milligramme), $l$. (litre), c.cm. or (as commonly employed by English writers) c.c. (cubic centimetre), c.mm. (cubic millimetre).

Decimal points should never be placed at the beginning of a number (thus .5 ); the form 0.5 should be used because the point may be overlooked by compositors and proofreaders or be broken in printing, thereby leading to regrettable or absurd errors.

Centigrade and Fahrenheit. Where the author has employed the Fahrenheit scale, the equivalent Centigrade measurement should be stated for the convenience of the majority of readers who employ the Centigrade scale. The Fahrenheit measurement should be given the second place in a bracket, thus: $100^{\circ} \mathrm{C} .\left(212^{\circ} \mathrm{F}\right.$.).

Whenever it is possible, authors are requested to end their papers with a brief Summary of the conclusions to which they have arrived. This is essential, especially with regard to lengthy papers.

All references should be given in full, either as footnotes or, particularly if there be many references, arranged alphabetically by authors at the end, the date of the paper being bracketed alongside the author's name. Cite also the volume and the page thus:

HaYward, T. E. (1902). On the construction and use of life-tables from a public health point of view. Journal of Hygiene, II. 1-42.

Authors will find it much easier in the end if they will cite the author by giving (in the text) the date and page of the paper referred to, thus: "Hayward (1902, p. 6) found, etc." By adopting this method, known as the "Harvard System," a new reference can be slipped into the MS. or proof without completely disturbing the order of references as is the case when papers are referred to in the text by the usual, but antiquated, method of citing the papers in accordance with the numbers to which they correspond in the list of references at the end of the paper. Moreover, the reader can readily be guided to the particular page whence the citation is derived.

The names of Journals and titles of books should be in italics (underline in MS.) and written out in full. The Editor will see that these names are abbreviated according to standard methods where necessary. Abbreviations like "B.M.J.," "J.R.A.M.C.," "Q.J.M.S.," "C.R.A.S.," are incomprehensible to many readers and a thorn in the side to Editors. By using Roman numbers for volumes and Arabic numbers for pages "vol." and "p." may be omitted, thus "xIr. 23" denotes vol. XII. p. 23, whereby needless type-setting is avoided. Authors should know that the abbreviations "T." in French and "Bd." in German stand for "vol."

In quoting the titles of Journals or books in languages other than English the writer should be particularly careful to see that the words are spelt correctly and that the proper accents, if any, are added to them. Much time is often lost in the endeavour to detect errors of this character in the final proofs, and also in rectifying them in the type.

Scientific names of animals and plants should be italicised in accordance with the rules of nomenclature, only the generic names should begin with Capitals, e.g. Bacillus diphtheriae, Ascaris lumbricoides, Trypanosoma brucei, etc.

Diagrams and Figures should always be accompanied by full descriptions or legends. 


\section{Illustrations.}

Illustrations constitute a most expensive item in publication. Authors should therefore select only those which are essential. Illustrations should never be placed in the text, they should be on separate sheets, the figures being clearly numbered in accordance with the numbered descriptions or legends.

Authors will be expected to contribute to the cost of their plates or to obtain grants covering a reasonable share of the expense entailed.

Authors should realise the great difference there is in the relativecost of various modes of illustration. If the cost of 500 copies of a plate reproduced by Coloured lithography requiring the use of six stones be taken as 100 , then the cost of the other processes commonly employed would work out somewhat as follows: Three-colour process, 75 ; Monochrome lithography, 50; Collotype, 42 ; Photolithography, 27; Halftone, 23 ; Line block, 11. Naturally the cost is governed in all cases by the amount of detail in the figures and their size when reproduced.

Plate illustrations. In the case of drawings, whether in colour, wash or line and stipple, the figures to be reproduced on plates should be executed on white drawing paper or card (avoid yellowish backgrounds) and neatly gummed on white card, being grouped and numbered in the order in which they are to appear in the published plate. Exclusive of margin, the plate figures, when reproduced, should not cover an area greater than $7 \frac{1}{2}$ inches in length and 5 inches $(19 \times 12.5$ cm.) in width in single plates, or greater than $7 \frac{1}{2}$ inches by $11 \frac{1}{2}$ inches $(19 \times 29$ $\mathrm{cm}$.) in double plates. Attention should be paid to the figures being grouped to the best advantage in respect to each other and the available space upon the plate.

Where photographs are to be reproduced by the half-tone process, a good positive is required, negatives are unsuitable. Photographs should be trimmed down so as to show what is essential only.

Line Blocks should be used whenever possible in place of the more expensive processes because they may be employed in the text, involve less trouble, and are the most suitable for reproduction in text-books. All drawings, diagrams, charts, maps, etc., intended for line-block reproduction should be sent flat and in a fit state for direct photographic reproduction. Any cost incurred in redrawing, lettering excepted, will be charged to the author. Illustrations should be pen drawings in Indian ink (jet black and water-proof) on smooth white Bristol board, the lettering being temporarily and lightly put in by the author with a soft pencil. It is best for the author to allow the skilled draughtsman or type-setter to deal with the final lettering. The size of the lettering inserted into the original drawing should be graded according to the degree of reduction that is desired in the final reproduction. All brush work, tinting, or pencil shading is to be avoided unless half-tones are required. Where the original figures require reduction, authors are advised to place a scale of measurement beside each figure so that the scale may be reproduced with the figure. Where considerable reduction is required, it is essential that the drawing should be of such a character as to bear such reduction. Authors should state to what degree the figures are to be reduced (by $\frac{1}{2}, \frac{1}{3}, \frac{1}{4}$, as the case may be). Text-figures, when reduced, should not occupy a space greater than the length and width of the printed surface of a page, e.g. 7 inches long by $4 \frac{3}{4}$ inches $(17.5 \times 12 \mathrm{~cm}$.) wide, allowing space for the accompanying legend. 
Charts and Curves are frequently drawn to best advantage on graph paper ruled in pale blue since, whilst ensuring accuracy, the blue lines do not appear in the photograph, only the blackened lines that are desired remaining.

\section{Proofsheets.}

Authors will receive one set of slip proof for correction and return to the Editor. An allowance of ten shillings per sheet of sixteen pages will be made for alterations apart from printer's errors. Authors will be charged for any excess over the amount stated.

\section{Reprints.}

Authors will receive 25 copies of their papers free. Additional copies, not exceeding one hundred (except in special cases), may be had at cost price; these should be ordered when the final proof is returned.

G. H. F. N. 


\section{CAMBRIDGE UNIVERSITY PRESS}

\section{Insect Pests and Fungus Diseases of Fruit and Hops.}

A complete manual for growers. By Percival J. Fryer, F.I.C., F.C.S., Director and Chief of Research Department, Yalding Manufacturing Co., Ltd.; Member of Society of Economic Biologists. Crown 8vo. With 24 plates (20 in colour and 4 in black and white) and 305 original photographs and diagrams. $45^{s}$ net.

\section{The Transmutation of Bacteria.}

By S. Gurney-Dixon, M.A., M.D., M.R.C.S., L.R.C.P. Demy 8 vo. $\operatorname{ros} 6 d$ net.

\section{Food Poisoning and Food Infections.}

By William G. Savage, B.Sc., M.D., D.P.H., County Medical Officer of Health, Somerset. Demy 8vo. I $_{5}$ net. Cambridge Public Health Series.

\section{The Bacteriological Examination of Food and Water.}

By William G. Savage. Second edition. Demy 8vo. With r6 illustrations. ros net. Cambridge Public Health Series.

\section{Flies in Relation to Disease: Non Blood=sucking Flies.}

By G. S. Graham-Smith, M.D., F.R.S. Second edition. Revised and enlarged. With 27 plates, 32 text figures, and 20 charts. Demy 8 vo. I $5 s$ net. Cambridge Public Health Series.

\section{Flies in Relation to Disease: Blood=sucking Flies.}

By Edward Hindle, B.A., Ph.D. With 83 illustrations. Demy 8 vo. i $5 s$ net. Cambridge Public Health Series.

\section{The House-Fly: Its Structure, Habits, Development, Relation to Disease, and Control.}

By C. G. Hewitr, D.Sc. With 3 coloured plates, ror illustrations, and a map. Demy 8 vo. $x 8 s$ net. Cambridge Zoological Series.

\section{House Flies and how they spread Disease.}

By C. G. Hewitr, D.Sc. With 20 illustrations. Royal r 6 mo. Cloth $2 s 6 d$ net.

Leather $3^{s}$ net. Cambridge Manuals Series.

\section{Typical Flies.}

A Photographic Atlas of Diptera, including Aphaniptera. By E. K. PEarce.

With 155 photographs. Royal 8vo. Paper boards. 6s net.

\section{Fungoid and Insect Pests of the Farm.}

By F. R. Petherbridge, M.A., Biological Adviser, School of Agriculture, Cambridge. Large crown 8vo. With 54 illustrations. $5^{s} 6 d$ net. Cambridge Farm Institute Series.

\section{British Rust Fungi (Uredinales).}

Their Biology and Classification. By W. B. Grove, M.A. Demy 8vo. With 290 figures. I $7 s$ net.

Cambridge University Press, Fetter Lane, London, E.C. 4

$$
\text { C. F. Clay, Manager }
$$




\section{CONTENTS}

\section{(All rights reserved)}

KeILIN, D. On the Life-History of Helicosporidium parasiticum, n.g., n.sp., a new type of Protist parasitic in the larva of Dasyhelea obscura Winn. (Diptera, Ceratopogonidae) and in some other Arthropods. (With Plates IV-VI and 5 Textfigures). . . . . . . . .

Buxton, P. A. The External Anatomy of the Sarcoptes of the Horse. (With Plate VII and 22 Text-figures) . . . 114

Buxton, P. A. On the Sarcoptes of Man. (With 9 Text-figures) 146

HINDLE, EdWARD. Notes on Rickettsia . . . . . 152

Stewart, F. H. The Anatomy and Biology of the Parasitic Aphelenchi. (With Figures 1, 2 on Plate VIII and Figures 3-32 in Text). . . . . . . . .

Keilin, D. Supplementary Account of the Dipterous Larvae feeding upon Molluses . . . . . . .

Nuttall, George H. F. and Keilin, D. On the Nephrocytes of Pediculus humanus. (With 5 Text-figures) . . .

Portrait Plates II-IV: Francesco Redi, Carolus Linnaeus, CarL DE GEer

Notice to authors of papers intended for publication in Parasitology

PARASITOLOGY is published about four times a year. The numbers afterwards are issued in volumes each containing four numbers.

Papers for publication should be sent to Professor George H. F. Nutrall, F.R.S., Longfield, Madingley Road, Cambridge. Other communications should be addressed to the University Press, Cambridge.

Papers forwarded to the Editors for publication are understood to be offered to PARASITOLOGY alone, unless the contrary is stated.

Contributors receive fifty copies of their papers free. Additional copies, not exceeding one hundred (except in special cases), may be had at cost price : these should be ordered when the final proof is returned.

The subscription price is $£ 2$. $5 s$. per volume (post-free), payable in advance; single numbers 158 . net (double number 30 s. net). Subscriptions may be sent to any Bookseller, or to Mr C. F. CLAY, Manager, Cambridge University Press, Fetter Lane, London, E.C. 4.

The Cambridge University Press has appointed the University of Chicago Press agents for the sale of Parasitology in the United States of America and has authorised them to charge the following prices: Subscription $\$ 9.00$ net per volume; single numbers $\$ 3.00$ net each, double numbers $\$ 6.00$ net each.

CAMBRIDGE : PRINTED BY J. B. PEACE, M. A., AT THE UNIVERSITY PRESS. 